\title{
Supervision and control prototyping for an engine exhaust gas heat recovery system based on a steam Rankine cycle
}

\author{
Paolino Tona, Johan Peralez and Antonio Sciarretta ${ }^{1}$
}

\begin{abstract}
Rankine-cycle waste heat recovery systems for automotive applications have been the focus of intensive research in recent years, as they seem to offer considerable potential for fuel consumption reduction. Because of the highly transient conditions they are subject to, control plays a fundamental role to enable viability and efficiency of those systems. Yet, surprising little research has been devoted to this topic.

This paper illustrates the design of a practical supervision and control system for a pilot Rankine steam process for exhaust gas heat recovery from a spark-ignition engine. The proposed control strategy for power production focuses more on ensuring continuity of operation than on the pursuit of optimality. The resulting decentralized control system is implemented via two anti-wind up controllers with feedforward action.

Performance has been assessed in simulation on a motorway driving cycle using real engine exhaust data. Despite very transient exhaust gas conditions, we show that the expander can produce power throughout the cycle, avoiding start-stop procedures, which would greatly reduce the global efficiency.
\end{abstract}

\section{INTRODUCTION}

About $30 \%$ of the energy produced by internal combustion engines (ICE) is released as heat to the atmosphere, through the exhaust gases. Though only a small fraction of it can be converted into high-quality, usable energy (exergy, in thermodynamic terms), a potential exists for recovering wasted heat in order to reduce fuel consumption in ICE-powered vehicles. Among the possible heat recovery solutions, turbo-compound is nowadays a standard technology for Diesel engines. Other solutions, involving thermoelectricity or thermodynamic cycles, have also been investigated during the last few years.

More particularly, waste heat recovery (WHR) systems based on the Rankine thermodynamic cycle have been the focus of intensive research for road transportation applications. To mention a few examples, BMW ([1], [2]), Honda ([3], [4]) and Ford [5] have recently

${ }^{1} \mathrm{P}$. Tona, J. Peralez and A. Sciarretta are with the Control, Signal and System Department at IFP Energies Nouvelles, France \{paolino.tona, johan.peralez, antonio.sciarretta\} eifpen.fr worked on this topic for cars, Cummins [6], Caterpillar [7], Daimler Trucks [8] and Volvo [9] for trucks. The interest of manufacturers is justified by announced reductions in fuel consumption ranging from 5 to $10 \%$, depending on the system and the driving cycle.

However, despite the development of several Rankine system prototypes for road transport, with few of them even making their way to demo vehicles, it is still unclear how viable and efficient these systems can be in real-world applications. In practice, these systems often struggle to attain satisfactory performance over a broad range of (transient) operating conditions.

One of the reasons why Rankine systems do not yet live up to their promises, is that they are most often designed for nominal performance in steady state, without taking into account the (highly) transient conditions they are subjected to when plugged to a powertrain. The question of how to control (or even, how controllable $i s$ ) the resulting system is seldom raised at early stages. Eventually, if the heat recovery system has to be shut down too often and/or it takes too long to attain power production conditions, expected gains will vanish.

Control plays a fundamental role to enable viability and efficiency of Rankine-cycle WHR systems for automotive applications. Despite this, surprising little research has been devoted to this topic.

This paper illustrates the design of a supervision and control system for a pilot Rankine steam process for exhaust gas heat recovery from a spark-ignition (SI) engine, from a prototyping point of view. This means that the supervision and control system is developed and validated in a realist framework to make it ready for testing on the experimental bench.

Section II presents the context of Rankine-based waste heat recovery for automotive applications and the state of the art on the control of such systems. Section III describes the Rankine steam process under consideration. Section IV gives a brief overview on the models used for control prototyping while section $\mathrm{V}$ describes more thoroughly the supervision and control system. Section VI describes the co-simulation framework and provides some illustrative simulation results. A few concluding 
remarks, putting this work in perspective, end the paper.

\section{CONTEXT AND STATE OF THE ART}

\section{A. Rankine systems for automotive applications}

The Rankine cycle is a thermodynamic cycle which converts heat into work. An external heat source supplies heat to a working fluid which circulates in a closed loop, via a heat exchanger (or a series of heat exchangers). Expansion of vaporized fluid (generally via a turbine) produces mechanical power. Vapor is then converted into liquid in a condenser which transfers heat to an external cold sink. A pump circulates the fluid at the required pressure. Most power plants in the world are steam powered and use this kind of cycle to generate power.

Typically, Rankine-based heat recovery systems for automotive applications have the layout shown in Figure 1.

To be viable, these systems must be lightweight and compact. Thus, heating, vaporization and superheating of the fluid usually take place in a single heat exchanger, the evaporator. The evaporator, whose hot gas inlet is usually "plugged" on the exhaust line, downstream of the after-treatment system, must be designed to interfere as little as possible with engine operation (low pressure drop). With regard to the condenser, the thermal capacity of the external heat sink will necessarily be (very) limited compared to that of a power plant.

The expander can be a positive-displacement device (reciprocating engine, scroll expander) or a turbine. It is arguably the most difficult component to design, as it must have high efficiency over a very broad operating range.

In most cases, Rankine systems for automotive applications are designed to produce electricity via a generator connected to the auxiliary network and/or an energy storage system, although produced mechanical

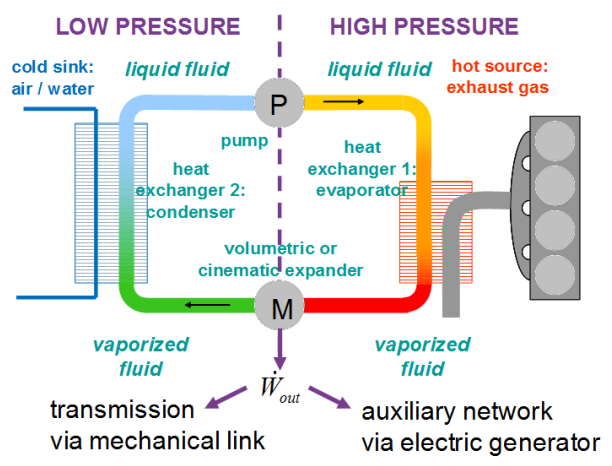

Fig. 1. Rankine WHR system layout for automotive applications power can be used directly via a mechanical connection to the transmission (as in [9]).

Practical Rankine systems for waste heat recovery from Diesel engines use organic, high molecular mass fluids, such as hydrofluorocarbons (HFCs), which boil at lower temperatures than water. Water can still be used as a working fluid to recover heat from the exhaust gas of spark-ignition engines, whose temperatures are considerably higher.

\section{B. Control issues}

In power plants, the role of the control system is mainly to regulate the power delivered by the turbinegenerator to a power grid, while guaranteeing the best efficiency conditions (maximizing heat transfer in the evaporator and using the turbine on optimal operating points). The first objective can be achieved by controlling the enthalpy flow rate from the hot source, which essentially means controlling the mass flow rate of fuel to be burnt in the plant. The second objective can be approached by "moving" the corner points (see Figure 4 in the following) of the thermodynamic cycle (adapting the mass flow rate of working fluid and, whenever possible, expander speed).

Control is not trivial because of the multivariable and coupled nature of the process, and becomes even more difficult in the waste heat recovery case, since the enthalpy flow rate from the hot source depends on the current use of the engine: it cannot be directly manipulated, but acts instead as a (measured) disturbance to the control system. Disturbances to the control system are also the cooling capacity of the heat sink, which might be partially controllable but is always limited, and the power request from the vehicle electrical network, whose handling may be more or less difficult than in the power plant case, depending on the smoothing capacity of the interface with the network. Additional difficulties arise from the safe operating range of each component, which can be quite limited in terms of admissible temperatures, pressures and vapor qualities. Last but not least, available on-board measurements and computational power are also limited.

The control system will benefit from more or less control authority depending on the architecture of the underlying Rankine process. Within the available degrees of freedom, only a well-designed control strategy will allow the WHR system to develop its full potential in real-world conditions.

\section{State of the art}

During the last few years, many research papers have been published on the topic of Rankine-based 
engine waste heat recovery systems for transportation applications. Most of them are dedicated to design issues (structure, components, working fluid) and to potential assessment (good examples are [10], [4], [1], [11], [12]). Papers on control issues are, on the other hand, surprisingly few in number.

The most detailed paper we have found in our literature review is [3], from Honda, where the authors present a Rankine system for waste heat recovery from a SI engine in a hybrid powertrain, using water as working fluid and a positive-displacement expander to produce electric power (via an integrated generator). Experimental results are provided for a decentralized control system composed of two proportional controllers with feedforward. Pump speed and expander speed are used as actuators to control respectively temperature and pressure of steam at evaporator outlet.

A more generic overview of control issues for Rankine-based WHR systems in vehicles is given in [13]. The impact of architecture on control authority is underlined, as well as the potential of using certain physical variables, such as system pressure, as actuators to improve system efficiency or energy recovery.

More recently, in [14], a complete start-up and shutdown procedure is described for a Rankine cycle system with ethanol as working fluid, for heavy-duty applications. The test bench is then operated manually, adjusting pump speed to sweep different operating points of the system.

On the more general topic of Organic Rankine Cycles (ORC) for waste heat recovery operating with variable heat sources (not necessarily for transport applications), [15] covers dynamic modeling and control of an ORC system with R234fa as a working fluid. Evaporating temperature and superheat ${ }^{1}$ are controlled by two PI controllers, using respectively expander speed and pump speed as actuators. Simulation results are given, which show acceptable performance. However, hot source variations used for simulation are much slower than those observed at the exhaust of an automotive engine, especially in terms of mass flow rate.

A somewhat richer literature exists on dynamic modeling and control of vapor compression cycles, the "reverse" of Rankine cycle, for air conditioning systems (see, for instance, [16] and the numerous papers of the Alleyne Research Group [17], [18], [19]). More particularly, in [18], a solid approach is presented for both modeling, with the use of simplified (movingboundary) heat exchanger models, and control design,

\footnotetext{
${ }^{1}$ Superheat is the number of degrees by which the temperature of superheated vapor exceeds the saturation temperature of the fluid.
}

with the development of control systems of increasing complexity (from decentralized PI-based control to multivariable $H_{\infty}$ synthesis) to improve performance.

\section{SYSTEM DESCRIPTION}

The system under consideration is a pilot Rankine steam process for recovering waste heat from a SI engine. Figure 2 shows its main components:

- volumetric pump;

- cross-flow evaporator;

- positive-displacement expander;

- steam - liquid condenser;

- $\operatorname{tank}$ (separator);

- evaporator by-pass valve;

- expander by-pass valve;

The latter two components are there to provide more degrees of freedom to control system operation. For instance, expander by-pass will be kept open as long as fluid condition at evaporator outlet are not safe for the expander. Whereas evaporator by-pass will be kept open as long as exhaust gas conditions are not favorable to heat recovery. With proportional by-pass valves, even more flexibility is provided to the control system.

Power produced by the positive-displacement expander is used by a generator (not shown) to produce electricity. Generator load can be controlled to allow expander speed adjustment.

With this set-up, the main actuators are:

- evaporator by-pass valve opening setpoint $V O_{\text {evap }}^{S P}$;

- expander by-pass valve opening setpoint $V o_{\text {exp }}^{S P}$;

- pump rotational speed setpoint $N_{p u m p}^{S P}$ (or, indirectly, water mass flow rate at pump outlet $\dot{m}_{\text {pump }}^{S P}$ );

- expander rotational speed setpoint $N_{\text {exp }}^{S P}$;

Pressure and temperature measurements are available at the inlet and outlet of each component. Controlled variables must be chosen among those measurements or combinations thereof.

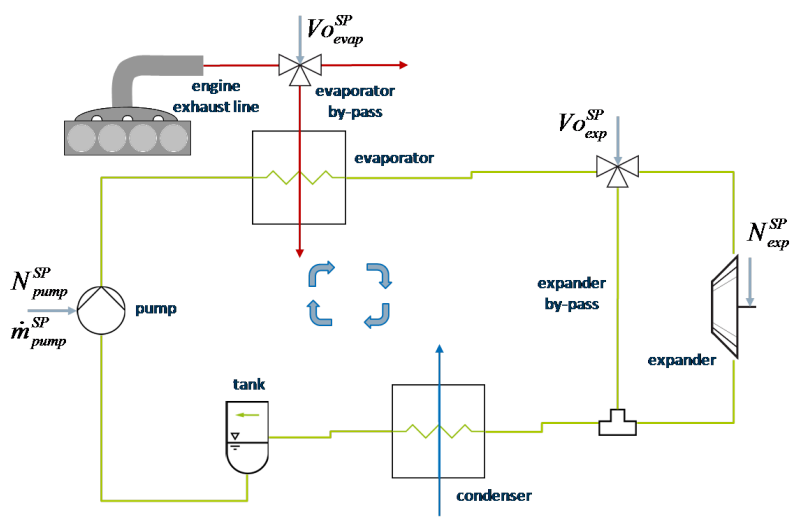

Fig. 2. Layout of Rankine steam process under consideration 


\section{MODELING}

A reference simulator has been developed for the Rankine system above, using TIL 2.1 [20], a Modelica [21] library for steady-state and transient simulation of thermodynamic systems. Blocks implementing finitevolume (FV) models are used for the two heat exchangers, to describe accurately their two-phase behavior. For control prototyping purposes, another, simpler simulator has been developped, replacing finite-volume models with moving-boundary (MB) models ([22], [23]). In MB models, separate control volumes (zones) for twophase and single phase fluid flow are defined, whose boundaries change dynamically, and zone lengths become dynamical states.

If well-coded, MB models allow the development of faster and more robust simulator while retaining accuracy. In Figure 3, results from the two simulators are compared, with a given exhaust enthalpy flow $\dot{H}_{e x h}$, in terms of superheat $S h_{\text {evap }}$ and pressure $p_{\text {evap }}$ of water at evaporator outlet, with respect to expander speed $N_{\text {pump }}$ and pump mass-flow $\dot{m}_{\text {pump }}$.

For reasons of space, the resulting differentialalgebraic system of equations (with 19 dynamical states) is not presented in this paper. The modeling approach for each component is similar to that adopted in [23].

\section{CONTROL SYSTEM}

\section{A. Overall structure}

The control system, coded in Simulink, has a base sampling period of $20 \mathrm{~ms}$, allowing proper filtering and controller discretization. It is composed of four main modules: Sensors, Actuators, Supervisor and control. The Sensors module is used to filter

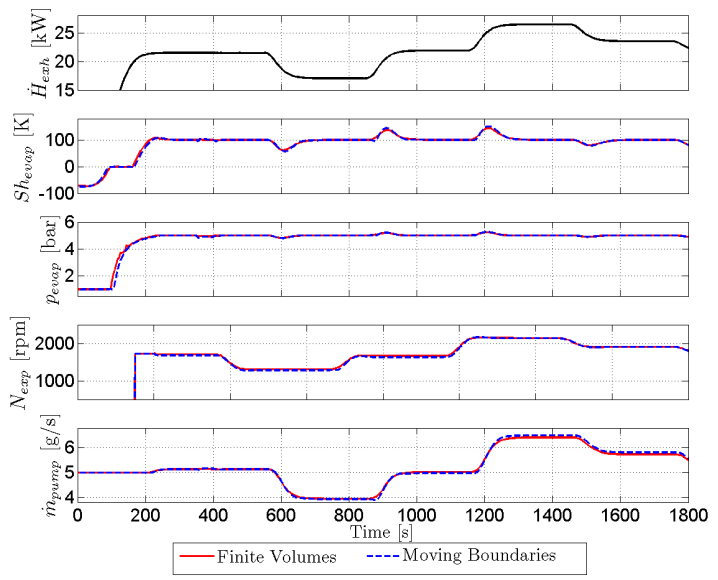

Fig. 3. Comparison between FV and MB models. Closed-loop control is switched on at $t=250 \mathrm{~s}$. available measurements and compute or estimate thermodynamic variables (enthalpy flow rate, superheat, subcooling) from those measurements. The Actuators module translates high-level commands to appropriate actuator setpoints. The Supervisor module implements safeties and manages the following system modes:

- Stop: exhaust gas (not hot enough) bypasses the evaporator;

- Cold idle: exhaust gas enters the evaporator while pump circulates fluid ( $S h_{\text {evap }}$ not yet positive);

- Hot idle: fluid conditions at evaporator outlet permitting the use of the expander are targeted;

- Expander start-up: expander bypass is closed and expander speed controlled;

- Power-production: nominal mode, in which the system should stay as much as possible;

- Expander shut-down: expander bypass is open and expander speed is brought to zero.

Each mode activates a specific (open-loop or closedloop) control strategy implemented in the Control module. Only the strategy for the power-production mode, the most important and complex to control, is detailed in the following.

\section{B. Control strategy for power-production mode}

As for any other heat recovery system, the control strategy must meet two core requirements: maximizing efficiency (i.e. recovering as much energy as possible) and ensuring component safety. In the power-production mode defined above, the pump and the expander, with their speed servos, provide two degrees of freedom to control two key variables : pressure $p_{\text {evap }}$ and superheat $S h_{\text {evap }}$ at evaporator outlet.

The cycle efficiency is defined as the ratio between the net work output (i.e. the work produced by the expander minus the work required by the pump, the latter being practically negligible), and the heat supplied by the exhaust gas to the working fluid.

The cycle representation on the $p-h$ diagram of Figure 4 shows that specific enthalpy at expander outlet $\left(h_{2}\right)$, should be as low as possible. But if the saturated vapor line is crossed, there will be liquid water in the expander. The tolerable value for vapor quality $x_{\exp }$ at point 2, depends on the expander technology. In our case, we will try to maintain $x_{\exp }$ close to unity, a compromise between efficiency and expander protection.

At expander inlet (that is, at evaporator oulet), for a given fluid pressure, there is one superheat value that yields unity vapor quality at expander outlet. This value will be used as a reference $S h_{\text {evap }}^{\text {ref }}$ for our controller.

As to the evaporator outlet pressure setpoint, steadystate analysis shows that there exists an optimal value 


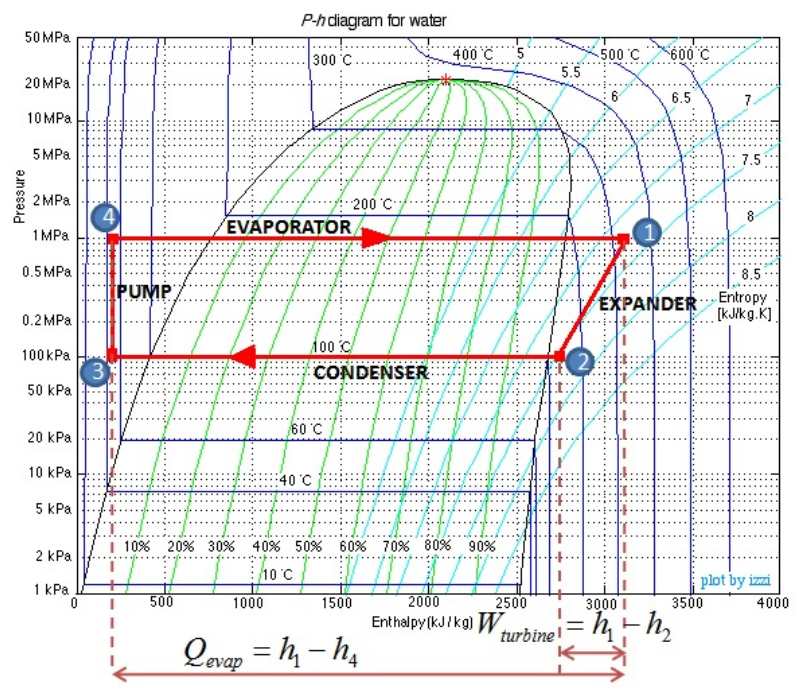

Fig. 4. Rankine cycle on water $p-h$ diagram

$p_{\text {evap }}^{\text {opt }}$ for cycle efficiency. $p_{\text {evap }}^{\text {opt }}$ depends in particular on exhaust gas temperature and mass flow rate. It could be tempting to use this optimal value as a setpoint, as proposed in [3] and [15]). In our opinion this approach, based on steady-state considerations, is questionable because

1) highly-transient external conditions imposed by real usage imply that the system never reaches an equilibrium state;

2) system response times to control actions vary significantly with operating conditions (due to strong non-linearities of the evaporator, as emphasized by [18]).

In fact, in the presence of a fast-varying hot source, trying to ensure the tracking of an optimal pressure trajectory at evaporator outlet affects the performance of superheat control, and may thus endanger the system. If, eventually, superheat $S h_{\text {evap }}$ could not be regulated to a safe value, expander would be shut down, and the overall performance would be affected.

This is why we prefer to free $P_{\text {evap }}$ from any optimality constraint and make it track instead a reference $P_{\text {evap }}^{\text {ref }}$ computed to help superheat control perform better. The objective becomes to control superheat $S h_{\text {evap }}$ as well as possible, while keeping $P_{\text {evap }}$ in the permissible operating range for the expander (between 5 and 15 bar in our case).

To do this, let us represent in a $p-S h$ diagram (Figure 5) the characteristic curve of the isentropic efficiency of the expander, connecting points 1 and 2 of the $p-h$ diagram of Figure 4 . We have seen that the superheat reference $S h_{\text {evap }}^{\text {ref }}$ must lie on the curve

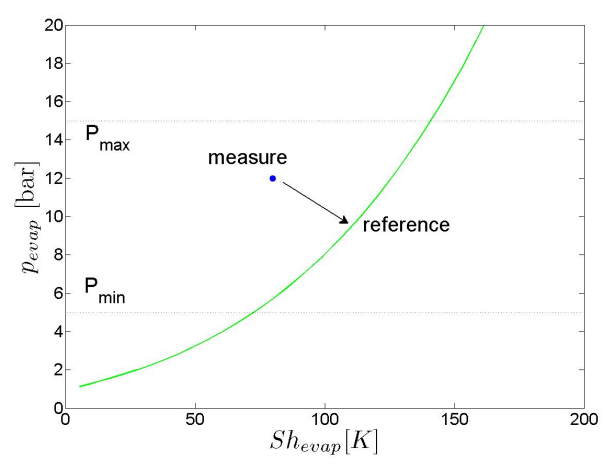

Fig. 5. Reference generation using the $p-S h$ equivalent of the expander isentropic efficiency characteristic

to ensure unity vapor quality at point 2 . Likewise, the pressure reference $p_{\text {evap }}^{\text {ref }}$ is taken on this curve in order to form the reference pair $\left(p_{\text {evap }}^{r e f}, S h_{\text {evap }}^{r e f}\right)$, with $P_{\text {min }}<$ $p_{\text {evap }}^{r e f}<P_{\text {max }}$, to comply with the expander operating range. The interest of using pressure in superheat control is explained by the physical link between pressure and evaporation temperature: decreasing the pressure makes the evaporation temperature decrease and therefore the superheat increase.

Note that the cycle of Figure 4 and the reference generation strategy of Figure 5 are obtained based on several simplifying assumptions, which include neglecting pressure drops in the heat exchangers, neglecting underexpansion and over-expansion losses in the expander and considering isentropic efficiency speed-independent. The latter may prove to be a strong assumption for positivedisplacement expanders.

\section{Implementation in a decentralized control scheme}

Implementing the strategy above requires designing a controller for a two-input two-output (TITO) system. A coupling analysis on the linearized system (similar to that presented in [19] for a vapor compression cycle) shows that it is possible to design a decentralized control system with the following input-output pairing: $\left\{\dot{m}_{\text {pump }}^{S P}\right.$ $\left.-S h_{\text {evap }}\right\}$ and $\left\{N_{\text {exp }}^{S P}-S h_{\text {evap }}\right\}$.

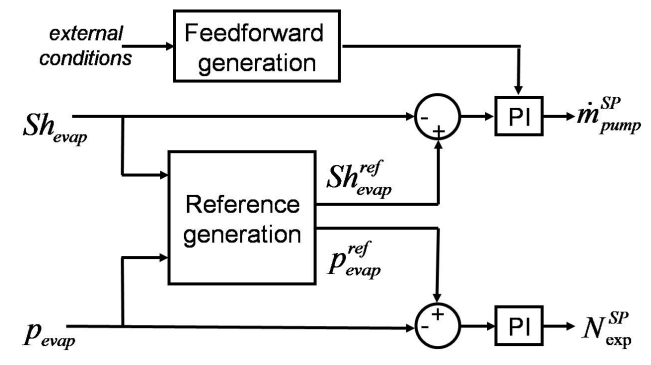

Fig. 6. Decentralized control scheme 
The resulting control scheme, shown in Figure 6, is based on two anti-wind up PI controllers (with the quite standard implementation structure described in [24]). Initial tuning is performed on reduced linear models computed around the main design operating point. A feedforward action on the pump is added to improve superheat control performance.

\section{SIMULATION RESULTS}

In the co-simulation set-up shown in Figure 7, the control system in Simulink is plugged to the Rankine cycle simulator in Dymola. External conditions for the evaporator and the condenser can be defined to simulate different scenarios.

To asses the performance of the control system we use exhaust mass flow rate and temperature profiles corresponding to on-highway vehicle use, which is arguably the most favorable case for waste heat recovery. These profiles come from experimental data recorded on a "Engine-in-the-Loop" test-bench used to evaluate hybrid architectures in the framework of the HyHiL project [25]. Data correspond to a conventional powertrain architecture (Renault Megane SCENIC II with a 2.0-liter turbocharged SI engine) tested on a (warm) Artemis Motorway Cycle (Figure 8).

As shown in Figure 9, exhaust conditions are far from being constant. On the condenser side, we have assumed a steady increase of coolant temperature during the test.

Plots in Figure 10 show that superheat and pressure at evaporator outlet are controlled satisfactorily. Pressure is kept inside the safe operating range for the expander. Notice that the manipulated variable $N_{e x p}^{S P}$ saturates at $500 \mathrm{rpm}$ and $2500 \mathrm{rpm}$ to comply with expander speed limitations.

As shown in Figure 11, once started, the expander can produce power throughout the rest of the cycle,

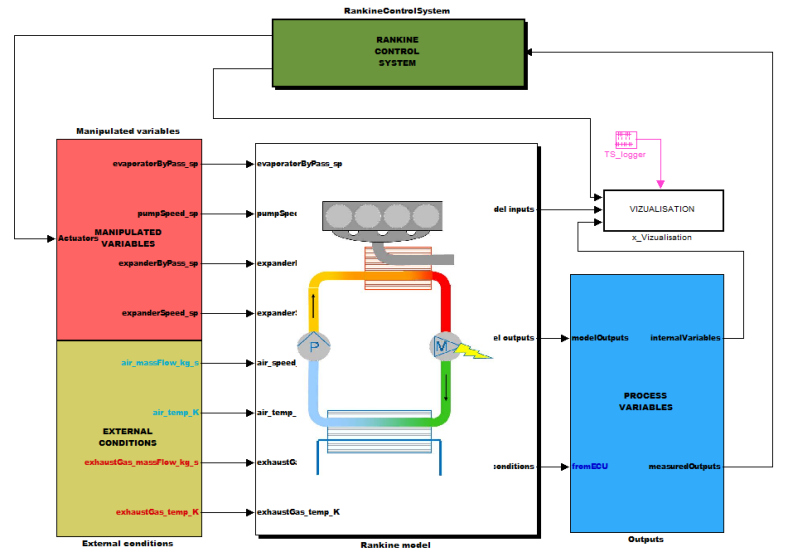

Fig. 7. Co-simulation set-up

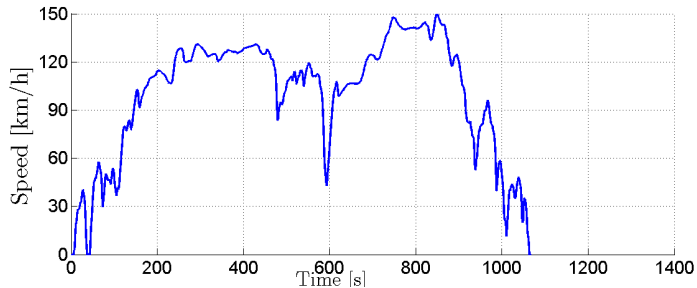

Fig. 8. Speed profile for the Artemis Motorway Cycle

and this even when the exhaust mass flow rate drops to zero, thanks to the inertia of the system. Thus, startstop procedures, which would greatly reduce the global efficiency of the cycle, are avoided.

\section{CONCLUSIONS}

We have described a practical control system for a pilot Rankine steam process for engine exhaust gas heat recovery. Structure and design are original contributions, both for the supervision and control part. The control strategy favors the continuity of operation over the search for (steady-state) optimality.

Performance has been assessed in simulation on a motorway driving cycle, with exhaust conditions quite favorable to energy recovery in terms of available heat, but very transient indeed. Validation will be pursued both in simulation, on a broader range of driving profiles, and on the experimental test bench.

Improvements of the base control strategy could be obtained taking advantage of the available reduced model of the Rankine steam process. Robustness analysis and model-based control design are the subjects being considered for further research.

\section{ACKNOWLEDGEMENTS}

The authors wish to thank DGCIS for its financial support in the framework of the ITAE 2 projet OPENPROD.

\section{REFERENCES}

[1] J. Ringler, M. Seifert, V. Guyotot, and W. Hübner. Rankine cycle for waste heat recovery of IC engines. SAE Int. J. Engines, 2:6776, Apr 2009.

[2] R. Freymann, J. Ringler, M. Seifert, and H. Tilmann. The second generation turbosteamer. MTZ Worldwide Edition, 2, 2012.

[3] T. Endo, S. Kawajiri, Y. Kojima, K. Takahashi, T. Baba, S. Ibaraki, T. Takahashi, and M. Shinohara. Study on maximizing exergy in automotive engines. In SAE 2007 World Congress, number 2007-01-0257, Detroit, MI, USA, Apr 2007.

[4] M. Kadota and K. Yamamoto. Advanced transient simulation on hybrid vehicle using rankine cycle system. SAE Int. J. Engines, 1:240-247, Apr 2008.

[5] Q. Hussain. Organic rankine cycle for light duty passenger vehicles. In 2011 DEER Conference, Detroit, MI, USA, oct 2011. Ford Motor Company, light-duty. 

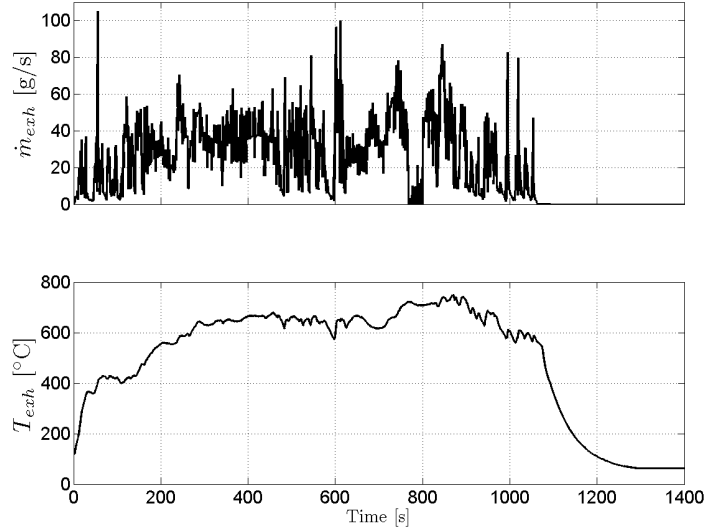

Fig. 9. Exhaust gas mass-flow and temperature profiles (data are extrapolated after $t=1068 \mathrm{~s}$ )
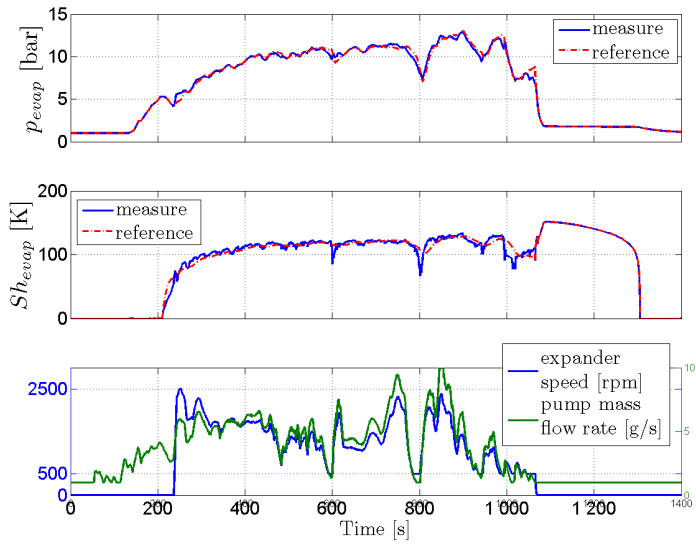

Fig. 10. Tracking performance
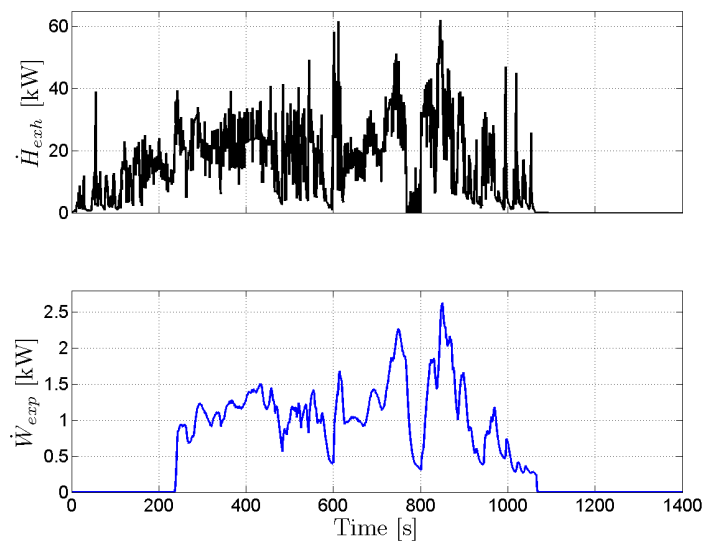

Fig. 11. Enthalpy flow rate in the exhaust gas vs. power produced by the expander
[6] C. Nelson. Exhaust energy recovery. In 2009 DEER Conference, Dearborn, MI, USA, Aug 2009. Cummins.

[7] R. Kruiswyk. An engine system approach to exhaust waste heat recovery. In 2010 DEER Conference, Detroit, MI, USA, Sep 2010. Caterpillar.

[8] S. Singh. Exhaust heat driven rankine cycle for a heavy duty diesel engine. In 2011 DEER Conference, Detroit, MI, USA, oct 2011. Detroit Diesel, Daimler Trucks.

[9] T. Howell. Development of an orc system to improve hd truck fuel efficiency. In 2011 DEER Conference, Detroit, MI, USA, oct 2011. Ricardo, Volvo.

[10] R. El Chammas and D. Clodic. Combined cycle for hybrid vehicles. In SAE 2005 World Congress, number 2005-01-1171, Detroit, MI, USA, Apr 2005

[11] A. Boretti. Recovery of exhaust and coolant heat with r245fa organic rankine cycles in a hybrid passenger car with a naturally aspirated gasoline engine. Journal of Applied Thermal Engineering, 36(0):73 - 77, 2012.

[12] H. Teng, T. Park, G.L. Hunter, and B. van der Velde. A rankine cycle system for recovering waste heat from HD diesel enginesWHR system development. In SAE 2011 World Congress, number 2011-01-0311, Detroit, MI, USA, Apr 2011.

[13] R.K. Stobart, S.M. Hounsham, and R. Weerasinghe. The controllability of vapour based thermal recovery systems in vehicles. In SAE 2007 World Congress, number 2007-01-0270, Detroit, MI, USA, Apr 2007.

[14] T. Park, H. Teng, G. Hunter, and B. et al. van der Velde. A rankine cycle system for recovering waste heat from HD diesel engines-experimental results. In SAE 2011 World Congress, number 2011-01-1337, Detroit, MI, USA, Apr 2011.

[15] S. Quoilin, R. Aumann, A. Grill, A. Schuster, V. Lemort, and H. Spliethoff. Dynamic modeling and optimal control strategy of waste heat recovery organic rankine cycles. Journal of Applied Energy, 2011.

[16] X.D. He, S. Liu, and H.H. Asada. Modeling of vapor compression cycles for multivariable feedback control of hvac systems. ASME Journal of dynamic systems, measurement, and control, 119:183, 1997.

[17] B. Rasmussen and A. Alleyne. Control-oriented modeling of transcritical vapor compression systems. ASME Journal of dynamic systems, measurement, and control, 126:54, 2004

[18] B Rasmussen. Dynamic modeling and advanced control of air conditioning and refrigeration systems. $\mathrm{PhD}$ thesis, University of Illinois at Urbana-Champaign, 2005.

[19] A. Alleyne, B. Rasmussen, M. Keir, and B. Eldredge. Advances in energy systems modeling and control. In American Control Conference, 2007. ACC'07, pages 4363-4373. IEEE, 2007.

[20] C. Richter. Proposal of new object-oriented equation-based model libraries for thermodynamic systems. $\mathrm{PhD}$ thesis, TU Braunschweig, 2008.

[21] P.A. Fritzson. Principles of object-oriented modeling and simulation with Modelica 2.1. Wiley-IEEE Press, 2004

[22] M. Gräber, N.C. Strupp, and W. Tegethoff. Moving boundary heat exchanger model and validation procedure. In EUROSIM Congress on Modelling and Simulation, Prague, Czech Republic, 2010.

[23] D. Wei, X. Lu, Z. Lu, and J. Gu. Dynamic modeling and simulation of an organic rankine cycle (orc) system for waste heat recovery. Journal of Applied thermal engineering, 28(10):12161224, 2008

[24] Karl Johan Åström and Tore Hägglund. PID Controllers: Theory, Design, and Tuning. Instrument Society of America, Research Triangle Park, North Carolina, 1995.

[25] A. Del Mastro, A. Chasse, P. Pognant-Gros, P.F. Corde, F. Gallo, and G. Hennequet. Advanced hybrid vehicle simulation: from "Virtual" to "HyHiL" test bench. In SAE 9th International Conference on Engines and Vehicles, number 2009-24-0068, Naples, Italy, Sep 2009. 